\title{
Parameter Optimization in the Synthesis of BZT Ceramics to Achieve Good Dielectric Properties
}

\author{
A. Frattini, ${ }^{1,2}$ A. Di Loreto, ${ }^{1,2}$ and O. De Sanctis ${ }^{2}$ \\ ${ }^{1}$ Área Física, Departamento de Química-Física, FCByF, UNR, Suipacha 531, 2000 Rosario, Argentina \\ ${ }^{2}$ Laboratorio de Materiales Cerámicos, FCEIyA, IFIR, UNR, Pellegrini 250, 2000 Rosario, Argentina
}

Correspondence should be addressed to A. Di Loreto; diloreto@fceia.unr.edu.ar

Received 14 November 2012; Revised 16 March 2013; Accepted 18 March 2013

Academic Editor: Antoni Morawski

Copyright (C) 2013 A. Frattini et al. This is an open access article distributed under the Creative Commons Attribution License, which permits unrestricted use, distribution, and reproduction in any medium, provided the original work is properly cited.

\begin{abstract}
The powder synthesis of barium zirconate titanate $(\mathrm{BZT})\left(\mathrm{BaZr}_{x} \mathrm{Ti}_{(1-x)} \mathrm{O}_{3}\right)$ from the mechanochemical activation of $\mathrm{BaCO}_{3}, \mathrm{ZrO}_{2}$, and $\mathrm{TiO}_{2}$ was studied. The grinding effect, by using a planetary ball milling, on the crystallization temperature of BZT powders $(x=0.05)$ was analyzed. X-ray diffractometry, differential thermal analysis, thermogravimetric analysis, and scanning electronic microscopy (SEM) were used as characterization methods. The crystallization behavior of powders activated by high-energy grinding and the effect of grinding time on the BZT crystallization were analyzed. After grinding by $4 \mathrm{~h}$, the $\mathrm{BaZr}_{(0.05)} \mathrm{Ti}_{(0.95)} \mathrm{O}_{3}$ sample was almost fully crystallized at $800^{\circ} \mathrm{C}$. The results of dielectric and ferroelectric properties show that high-energy ball milling is a practical and promising way to prepare BZT ceramics.
\end{abstract}

\section{Introduction}

Ferroelectric materials based in $\mathrm{Pb}$ have been studied for many years for its important applications in piezoelectric, pyroelectric, and optical devices [1-5]. Lead-free compositions can be of great interest for environmentally friendly applications such as actuators and dielectrics for capacitors. $\mathrm{BaTiO}_{3}$ is the most widely used ferroelectric material in ceramic capacitors and is known for its large electrochemical coupling factor $[2,3]$. Within $\mathrm{BaTiO}_{3}$ family, barium zirconate titanate $\left(\mathrm{Ba}\left(\mathrm{Zr}_{x} \mathrm{Ti}_{(1-x)}\right) \mathrm{O}_{3}, \mathrm{BZT}\right)$ has become one of the most attractive materials because it has been reported that the zirconium substitutions into the titanium lattices enhance the dielectric and piezoelectric properties [6,7]. Furthermore, Curie temperature can be shifted below room temperature by doping with $\mathrm{Zr}[8,9]$. However, under common preparation conditions, BZT ceramics have very high sintering temperature that does not fit the industrial requirements. In order to decrease the sintering temperature, it is necessary to produce powders with fine particle sizes and homogeneous distribution.

Mechanochemical activation by mixing of high energy (high-energy ball milling) has become important to produce solid-state reactions at lower temperatures than those used in conventional methods of powder preparation [10-14]. This mechanical technique is unique because of its advantages: (i) low cost of starting materials, (ii) low operating temperature, and (iii) higher sinterability of milled powders.

The purpose of this work is to reach low energy cost in the synthesis of BZT ceramics without expense of their electrical properties. The effects of increasing the milling time of the powders and, on the other hand, of lowering the powder calcination temperature and/or sintering temperature of the pellets are analyzed.

\section{Experimental}

BZT ceramics were prepared via conventionally mixed-oxide method by high-energy ball milling. Commercial powders of barium carbonate $\left(\mathrm{BaCO}_{3}\right)$ (99.98\% Sigma-Aldrich), titanium dioxide $\left(\mathrm{TiO}_{2}\right)$ (99.98\% Sigma-Aldrich), and zirconium oxide $\left(\mathrm{ZrO}_{2}\right)$ (99.9\% Sigma-Aldrich), were used as starting materials with the nominal composition of $\mathrm{BaZr}_{0.05} \mathrm{Ti}_{0.95} \mathrm{O}_{3}$. The precursors were ground in a planetary ball milling (Torrey Hills Technologies ND 0.4L) during 1, 2, and $4 \mathrm{~h}$, 
into a zirconia jars. Simultaneous differential thermal analysis (DTA) and thermogravimetric analysis (TGA) measurements were carried out on the as-obtained powder from $20^{\circ} \mathrm{C}$ to $1200^{\circ} \mathrm{C}$ at $10^{\circ} \mathrm{C} / \mathrm{min}$ heating rate, with $50 \mathrm{~mL} / \mathrm{min}$ of $\mathrm{O}_{2}$ flux into alumina crucibles, using a Shimadzu DTG-60 analyzer. The mixed powders were calcined between $600^{\circ} \mathrm{C}$ and $1200^{\circ} \mathrm{C}$ for $2 \mathrm{~h}$ in the air. Afterwards, powders were analyzed by X-ray diffraction (XRD-Philips PW1700 diffractometer), scanning electron microscopy (SEM Philips 505), and high-resolution SEM (FEI QUANTA 200).

The powders with two weight percent PVB binder were uniaxially pressed $(200 \mathrm{MPa})$ into green pellets with $10 \mathrm{~mm}$ of diameter and $1 \mathrm{~mm}$ of thickness. The sintering behavior of these pellets was monitored at constant heating rate $\left(5^{\circ} \mathrm{C} / \mathrm{min}\right)$ in a Theta Dilatronic dilatometer. Structural analyses of sintered samples at $1350^{\circ} \mathrm{C}$ and $1400^{\circ} \mathrm{C}$ were performed by XRD and SEM.

To measure the electric properties, the surfaces were polished, and silver electrodes were painted on both sides of the pellets. The capacitance and dielectric loss of the samples were measured with a HP 4192A impedance analyzer, and the hysteresis loops were examined by using a conventional Sawyer-Tower tester at $50 \mathrm{~Hz}$.

\section{Results and Discussion}

Figures 1 and 2 show the DTA-TGA curves of the oxides mixture milled for 1 and $4 \mathrm{~h}$, respectively, when they were heated from room temperature to $1200^{\circ} \mathrm{C}$. Three endothermic peaks (labeled as (1), (2), and (3)) are observed in both DTA curves. The first two peaks match with weight losses, whereas no weight loss is seen for the last one. It is well known $[15,16]$ that the first two peaks correspond to reactions of $\mathrm{BaCO}_{3}$ decomposition and synthesis of $\mathrm{BaTiO}_{3}$, including the formation of a transient $\mathrm{Ba}_{2} \mathrm{TiO}_{4}$ phase. These reactions are as follows:

$$
\mathrm{BaCO}_{3}+\mathrm{TiO}_{2} \longrightarrow \mathrm{BaTiO}_{3}+\mathrm{CO}_{2}
$$

where the $\mathrm{CO}_{2}$ emission causes the first weight loss realized in the TGA graph (around $600^{\circ} \mathrm{C}$ ),

$$
\mathrm{BaCO}_{3}+\mathrm{BaTiO}_{3} \longrightarrow \mathrm{Ba}_{2} \mathrm{TiO}_{4}+\mathrm{CO}_{2}
$$

where again there is weight loss by the $\mathrm{CO}_{2}$ emission, and

$$
\mathrm{Ba}_{2} \mathrm{TiO}_{4}+\mathrm{TiO}_{2} \longrightarrow 2 \mathrm{BaTiO}_{3}
$$

which has no weight loss associated.

By comparing both figures, it is noted that the peak (1) is broader and deeper in Figure 2 which means further development of reaction (1) in the sample milled by $4 \mathrm{~h}$ and matches with the greater mass loss (about double) observed in the TGA curve. This behavior also agrees with the smaller depth of peak (2) in Figure 2 since more $\mathrm{BaCO}_{3}$ has decomposed and also with the $800^{\circ} \mathrm{CXRD}$ patterns in Figures 3(a) and $3(\mathrm{~b})$, where it is quite clear that there is fewer remaining $\mathrm{BaCO}_{3}$ in the sample milled for $4 \mathrm{~h}$.

It is noteworthy that the formation of $\mathrm{Ba}_{2} \mathrm{TiO}_{4}$ phase advances at the temperature range between $600^{\circ} \mathrm{C}$ and $900^{\circ} \mathrm{C}$

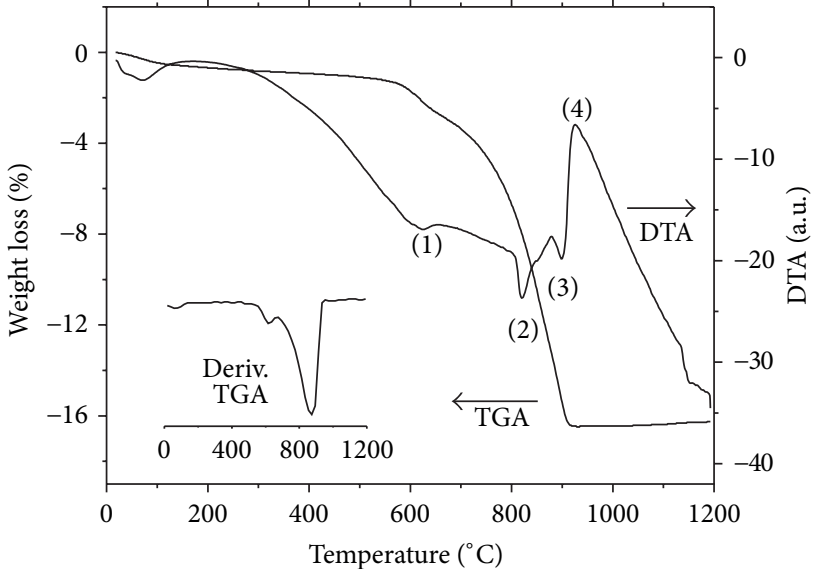

FIGURE 1: DTA-TG of BZT powder milled for $1 \mathrm{~h}\left(10^{\circ} \mathrm{C} / \mathrm{min}\right.$ heating rate, sample weight $=30.158 \mathrm{mg}$ ).

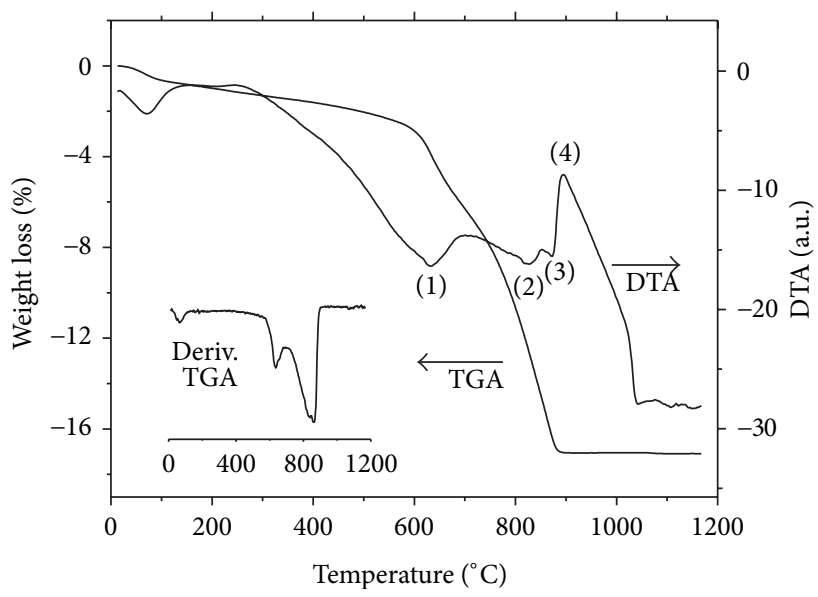

FIGURE 2: DTA-TG of BZT powder milled for $4 \mathrm{~h}\left(10^{\circ} \mathrm{C} / \mathrm{min}\right.$ heating rate, sample weight $=28.135 \mathrm{mg}$ ).

due to the diffusive nature of this reaction [15]. The peak (2) in Figure 1 is quite sharp since superposes the $\gamma \rightarrow \beta$ allotropic transition of $\mathrm{BaCO}_{3}$ (at $827^{\circ} \mathrm{C}$ ) [17] with reaction (2). As it is observed, this peak in Figure 2 is not so deep because that transition is hindered by the lattice deformation resulting of the greater milling time.

On the other hand, Figure 2 shows an increase in the mass loss rate (see the derivative of the TGA curve from the inset) because of the higher reactivity of the powders and the faster kinetic of the reaction. Furthermore, the mass loss finishes at $885^{\circ} \mathrm{C}$ in the $\mathrm{BZT}-4 \mathrm{~h}$ sample and at $920^{\circ} \mathrm{C}$ for the $\mathrm{BZT}$ $1 \mathrm{~h}$ one. By revising DTA graphs, only reaction (3) could be present from these temperatures until the maximum of hump (4). This temperature defines the synthesis of $\mathrm{BaTiO}_{3}$ after accomplishment of all the reactions above mentioned.

Berbenni et al. [18] have obtained a final plateau in its TG curve at $730^{\circ} \mathrm{C}$ by applying high-energy milling for $159 \mathrm{~h}$ on BZT powders. By analyzing the temperatures where the mass loss is over, Berbenni's results and ours indicate that crystallization starts at lower temperatures if more energy 


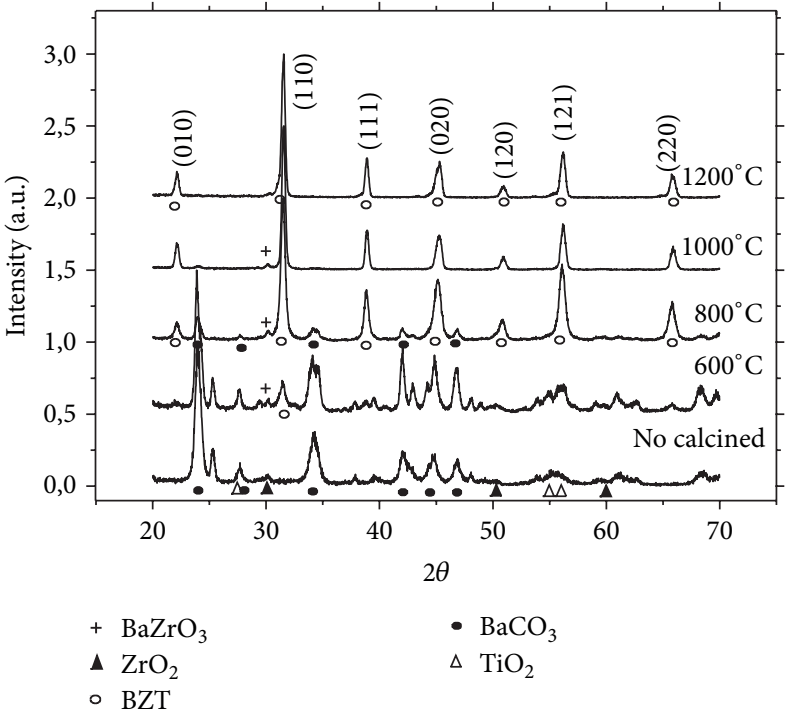

(a)

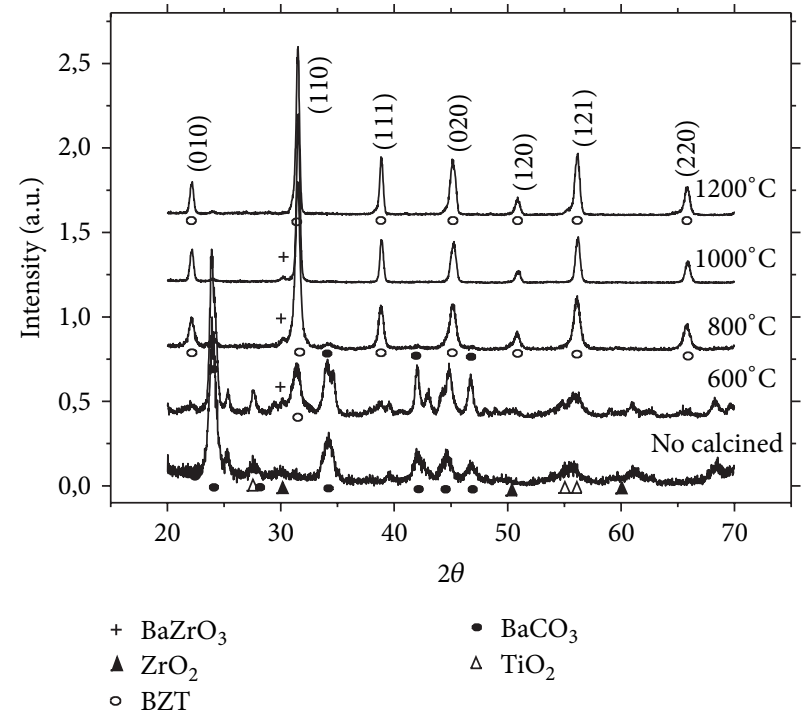

(b)

FIGURE 3: (a) XRD of $1 \mathrm{~h}$ milled powders as calcination temperature function. (b) XRD of $4 \mathrm{~h}$ milled powders as calcination temperature function.

from milling is delivered. That is to say, by increasing the milling time the powders will have more reactivity because of their smaller particle size and hence higher surface area. By comparing the end of hump (4) in both DTA curves, it is clear that the sample ground for $4 \mathrm{~h}$ has completely crystallized at $1040^{\circ} \mathrm{C}$. The sample milled for $1 \mathrm{~h}$ seems to be completely crystallized at $1200^{\circ} \mathrm{C}$. Finally, from Figures 1 and 2, it can be expected that $\mathrm{Ba}_{2} \mathrm{TiO}_{4}$ and $\mathrm{BZT}$ coexist only in samples calcined in temperatures ranging between $700^{\circ} \mathrm{C}$ and $900^{\circ} \mathrm{C}$.

XRD patterns of both samples (Figures 3(a) and 3(b)) are on good agreement with the DT and TG analysis. The diffractogram of $600^{\circ} \mathrm{C}$ for the $4 \mathrm{~h}$ milled sample shows the main peak of BZT sharper and higher than the one corresponding to the $1 \mathrm{~h}$ milled sample. The $800^{\circ} \mathrm{C}$ pattern for the $1 \mathrm{~h}$ ground sample (Figure 3(a)) shows clear presence of $\mathrm{BaCO}_{3}$ peaks yet $\left(23.89^{\circ}, 27.71^{\circ}, 34.08^{\circ}, 34.58^{\circ}, 41.98^{\circ}, 42.95^{\circ}\right.$, and $46.77^{\circ}$ ) while they have disappeared in the $4 \mathrm{~h}$ ground sample (Figure 3(b)).

Furthermore, in the $800^{\circ} \mathrm{C}-4 \mathrm{~h}$ ground XRD pattern (Figure 3(b)), the BZT seems to be practically crystallized; just some peaks of $\mathrm{BaCO}_{3}$ and the strongest of cubic $\mathrm{BaZrO}_{3}$ $\left(2 \theta=30.14^{\circ}\right)$ are weakly seen. At $1000^{\circ} \mathrm{C}$, there only remains the main peak of $\mathrm{BaZrO}_{3}$, whereas, at $1200^{\circ} \mathrm{C}$, the sample is fully crystallized. Even though the DTA and TGA graphics have suggested possible presence of $\mathrm{Ba}_{2} \mathrm{TiO}_{4}$ phase between $800^{\circ} \mathrm{C}$ and $900^{\circ} \mathrm{C}$, this phase has not been detected in the XRD patterns. It is worth noting that XRD measurements were carried out on samples previously calcined for $2 \mathrm{~h}$, while thermal measurements have a quite different thermal evolution $\left(10^{\circ} \mathrm{C} / \mathrm{min}\right)$. The calcination for $2 \mathrm{~h}$ could have increased the $\mathrm{Ba}_{2} \mathrm{TiO}_{4}$ diffusion, and there it will be transformed completely into $\mathrm{BaTiO}_{3}$ [15].

Figure 4 shows the milling time effect on powders calcined at $1200^{\circ} \mathrm{C}$ for $2 \mathrm{~h}$. The peaks are broad, showing poorly crystallized phases with amorphous phases for unmilled

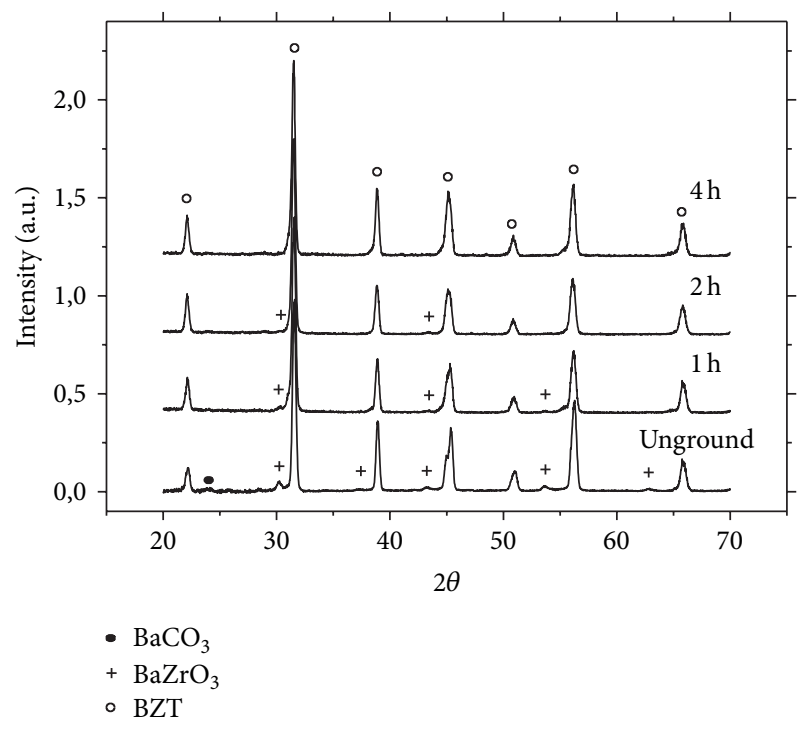

FIGURE 4: XRD of BZT powders milled during different times and calcined at $1200^{\circ} \mathrm{C}$ for $2 \mathrm{~h}$.

powders. They become stronger and sharper when the samples are milled. It is observed that the unground sample presents peaks corresponding to $\mathrm{BaCO}_{3}\left(2 \theta=24.09^{\circ}\right)$ and $\mathrm{BaZrO}_{3}\left(2 \theta=30.14^{\circ}, 37.14^{\circ}, 43.14^{\circ}, 53.54^{\circ}\right.$, and $\left.62.67^{\circ}\right)$. After grinding by 1 hour, the samples did not exhibit $\mathrm{BaCO}_{3}$, but, however, the $\mathrm{BaZrO}_{3}$ content decreased gradually as the milling time increased. Finally, a BZT structure free of spurious phases was obtained after $4 \mathrm{~h}$ of grinding and $2 \mathrm{~h}$ of calcination at $1200^{\circ} \mathrm{C}$. The crystallite sizes of powders calcined at different times were calculated from the X-ray broadening of (110) peaks, using the Scherrer equation [19]. Crystallite sizes for powders treated at $1 \mathrm{~h}, 2 \mathrm{~h}$, and $4 \mathrm{~h}$ are $32.9,33.8$, and 


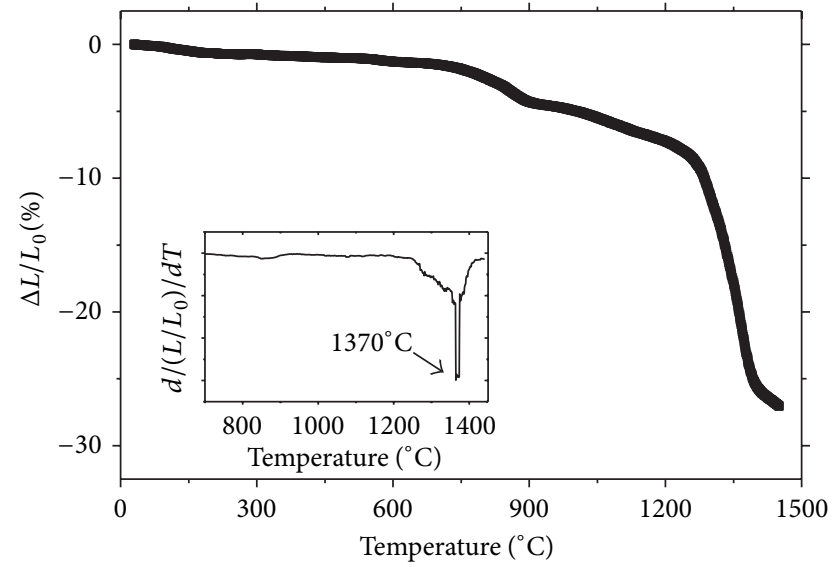

Figure 5: Linear shrinkage and linear shrinkage rate (inset) as a temperature function. The pellets were fabricated from powder calcined at $800^{\circ} \mathrm{C}$.

$35.7 \mathrm{~nm}$, respectively. This indicates that BZT crystallizes and grows as the milling time increases.

The curves of linear shrinkage and its derivative with respect to temperature $\left(d\left(\Delta L / L_{0}\right) / d T\right)$, both as functions of temperature, are shown in Figure 5. The first contraction between $750^{\circ} \mathrm{C}$ and $900^{\circ} \mathrm{C}$ indicates powder agglomeration during the sintering due to processes inside the agglomerates and between them [20]. Densification then increases sharply $(\sim 20 \%)$ in the range from $1250^{\circ} \mathrm{C}$ up to $1400^{\circ} \mathrm{C}$. From these data, the $1350^{\circ} \mathrm{C}$ and $1400^{\circ} \mathrm{C}$ values were set as suitable temperatures for the sintering of ceramic pellets.

The SEM from Figure 6(a) indicates that the average grain size of ceramic is $250 \mathrm{~nm}$, which means that grains have not grown in the sintering process with respect to the initial size of the crystallites in the powders (Figure 6(b)). However, certain porosity can be seen in the micrograph presumably induced by a binder evaporation and/or by a residual inhomogeneity in the shape of the calcined crystallites. Indeed, if the calcined crystallites are irregularly shaped prior to pressing, greater porosity will result in the sintered ceramic.

Figure 7 shows the XRD patterns of BZT pellets sintered at $1350^{\circ} \mathrm{C}$ and $1400^{\circ} \mathrm{C}$. BZT pellets sintered at $1400^{\circ} \mathrm{C}$ display full crystallization in a perovskite phase, while small peaks of secondary phase are noted in the sample sintered at $1350^{\circ} \mathrm{C}$. Moreover, larger grain growth is detected in the $1400^{\circ} \mathrm{C}$ sample. Precisely for both ceramics, crystallite sizes of $56.3 \mathrm{~nm}$ and $58.9 \mathrm{~nm}$ were calculated from half-width of (011) peaks.

The sintering temperature has significant influence on the electrical properties as displayed in Figure 8. The behavior of the dielectric constant $\left(\varepsilon_{r}\right)$ with frequency $[1 \mathrm{kHz}-1 \mathrm{MHz}]$ is similar in both samples $\left(1350^{\circ} \mathrm{C}\right.$ and $\left.1400^{\circ} \mathrm{C}\right)$, but their values are higher, in all this range, for the sample sintered at $1400^{\circ} \mathrm{C}$. The comparison between both samples in the range $1 \mathrm{kHz}-10 \mathrm{kHz}$ is reported at the inset. Furthermore, the dielectric loss $(D)$ in both samples decreases with the increasing frequency in this range, this value being lower for the sample sintered at $1400^{\circ} \mathrm{C}$. These two behaviors come from a further densification at higher temperature.

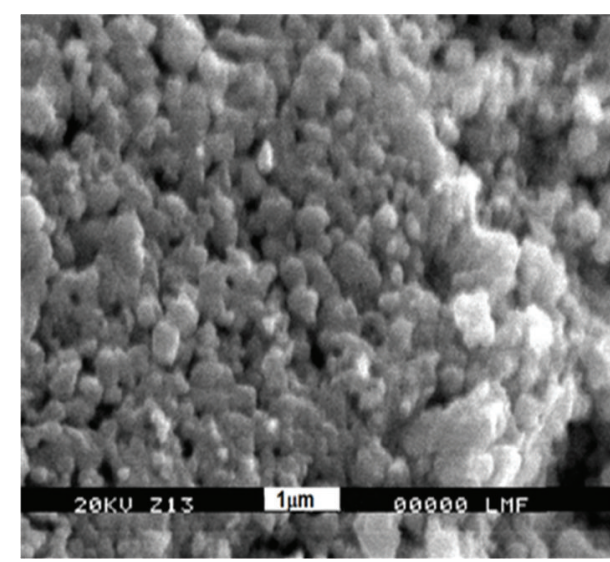

(a)

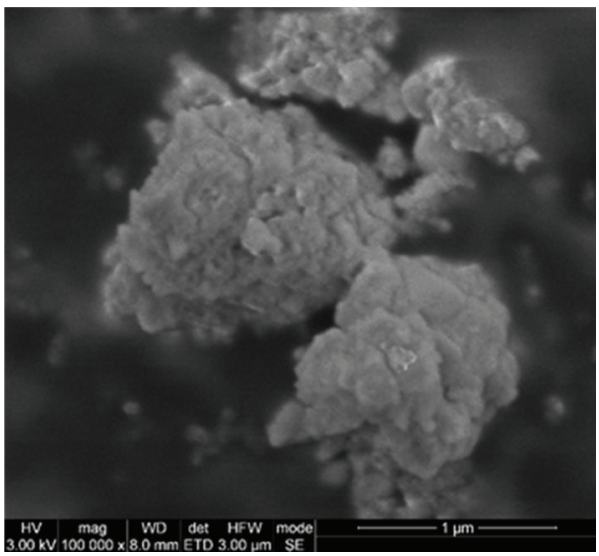

(b)

FIgURE 6: (a) SEM of the ceramic sintered at $1350^{\circ} \mathrm{C}$. (b) HRSEM of ground powders by $4 \mathrm{~h}$.

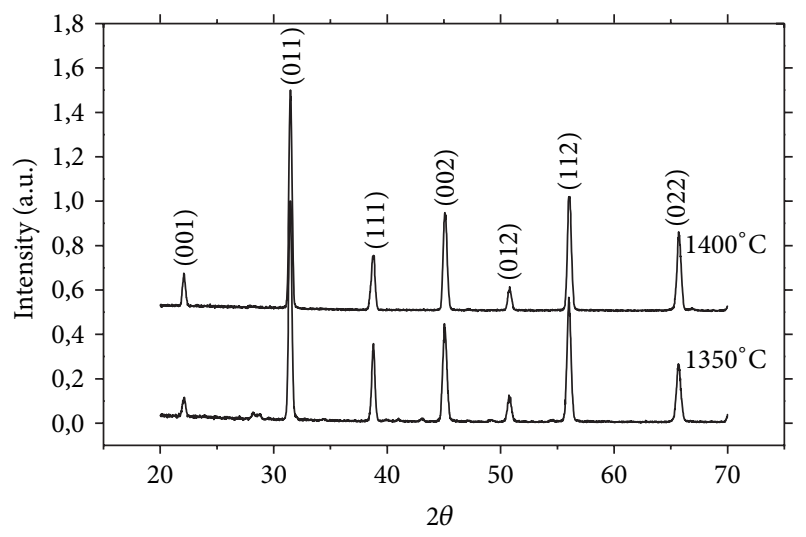

Figure 7: XRD of BZT pellets sintered at $1350^{\circ} \mathrm{C}$ and $1400^{\circ} \mathrm{C}$.

Figure 9(a) shows the dielectric constant evolution of the BZT sample (sintered at $1400^{\circ} \mathrm{C}$ ) with the temperature, where the three curves correspond to measurements at 10 , 50 , and $100 \mathrm{kHz}$. The ceramic presents two abrupt changes in dielectric constant corresponding to the orthorhombictetragonal $\left(\sim 60^{\circ} \mathrm{C}\right)$ and tetragonal-cubic $\left(\sim 125^{\circ} \mathrm{C}\right)$ phase transitions, displaying a typical ferroelectric behavior [21-23]. 


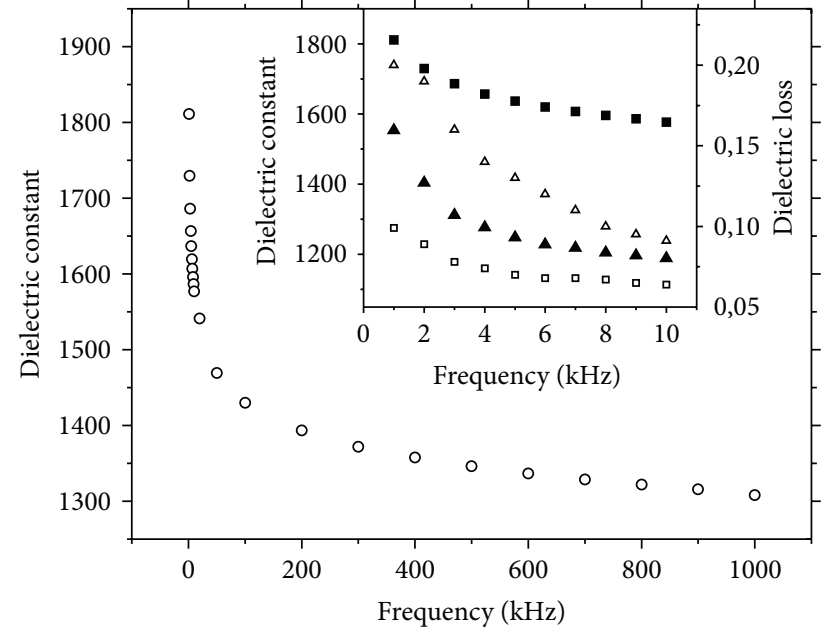

FIGURE 8: Dielectric constant $\left(\varepsilon_{r}\right)$ of BZT sintered at $1400^{\circ} \mathrm{C}$. Inset: zoom for $\{1-10 \mathrm{kHz}\}$ range, $\Delta: \varepsilon_{r}$ for sample sintered at $1400^{\circ} \mathrm{C}, \mathbf{\Delta}: \varepsilon_{r}$ for $1350^{\circ} \mathrm{C}$ sintered BZT, $\square$ : dielectric loss for $1350^{\circ} \mathrm{C}$ sintered BZT, -: dielectric loss for $1400^{\circ} \mathrm{C}$ sintered BZT.

Besides, it is not observed a $T_{C}$ shift (Curie temperature) with frequency, according to a nonrelaxor ferroelectric.

The Curie temperature increases slightly as does the sintering temperature; it can be seen in Figure 9(b). Moreover, the orthorhombic to tetragonal transition phase around $60^{\circ} \mathrm{C}$ is more evident in the sample sintered at $1400^{\circ} \mathrm{C}$.

The hysteresis cycle measured at $50 \mathrm{~Hz}$ and room temperature, with the sample inside of silicon oil, is shown in Figure 10. Typical performances of normal ferroelectrics, according to the designed ceramic composition, were observed. The sample sintered at $1400^{\circ} \mathrm{C}$ shows a remnant polarization of $35 \mu \mathrm{C} / \mathrm{cm}^{2}$ and a coercive electric field of about $2.5 \mathrm{kV} / \mathrm{cm}$, while the $1350^{\circ} \mathrm{C}$ sintered ceramic shows lower values in its ferroelectric properties.

These results can be compared to the dielectric constant and the ferroelectric P-E hysteresis loops previously reported. Nanakorn et al. [23] have obtained $25 \mu \mathrm{C} / \mathrm{cm}^{2}$ for remnant polarization and about 3000 as dielectric constant $\left(\varepsilon_{r}\right)$ in ceramics of BZT $(x=0.05)$. Their procedure involved ball milling in acetone during $24 \mathrm{~h}$, calcination at $1200^{\circ} \mathrm{C}$ for $2 \mathrm{~h}$, milling for $24 \mathrm{~h}$ in ethanol, and sintering at $1300^{\circ} \mathrm{C}-1450^{\circ} \mathrm{C}$ for $2 \mathrm{~h}$. Similar method has been used by Yu et al. [24] (except for sintering at $1500^{\circ} \mathrm{C}-1560^{\circ} \mathrm{C}$ from 2 to $15 \mathrm{~h}$ ) and they have found values of $13.3 \mu \mathrm{C} / \mathrm{cm}^{2}$ and $\varepsilon_{r}=1600$ for $\mathrm{BaZr}_{(0.05)}$ $\mathrm{Ti}_{(0.95)} \mathrm{O}_{3}$ ceramics.

\section{Conclusions}

The purpose of reaching low energy cost in the synthesis of BZT ceramics was achieved. By high-energy milling, suitable crystallization of $\mathrm{BaZr}_{0.05} \mathrm{Ti}_{0.95} \mathrm{O}_{3}$ powders was achieved at $800^{\circ} \mathrm{C}$ due to the increasing in their reactivity. From these powders, BZT ceramics were sintered for $2 \mathrm{~h}$ at $1350^{\circ} \mathrm{C}$ and $1400^{\circ} \mathrm{C}$. BZT ceramics with high values of remnant polarization $\left(35 \mu \mathrm{C} / \mathrm{cm}^{2}\right)$ and good values of dielectric constant $(1700$

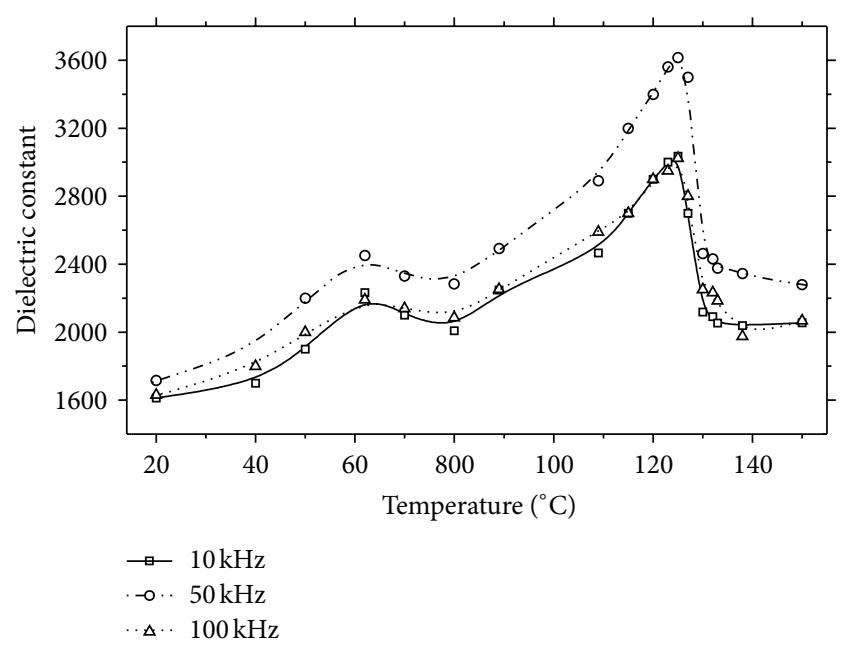

(a)

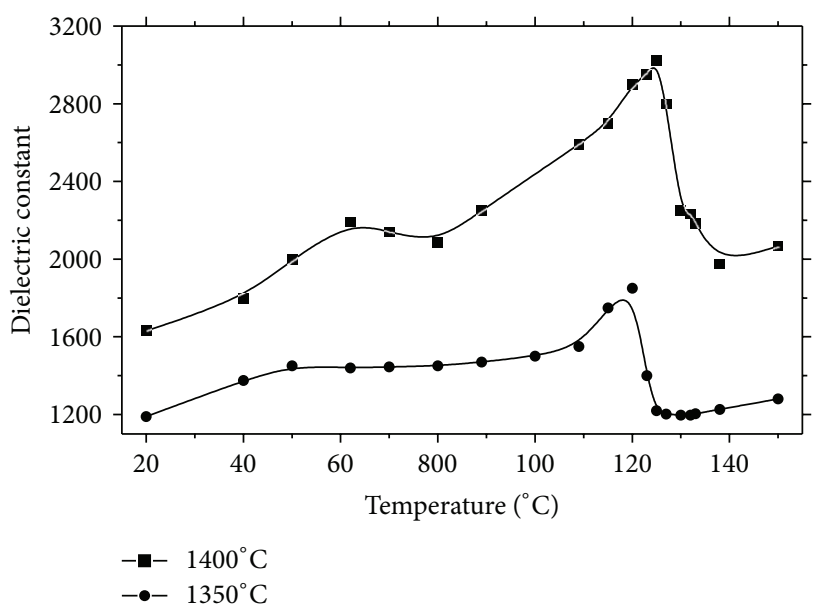

(b)

FIGURE 9: (a) Dielectric constant versus temperature and frequency for the sample sintered at $1400^{\circ} \mathrm{C}$, measured at room temperature. (b) Dielectric constant versus temperature for ceramics sintered at $1350^{\circ} \mathrm{C}$ and $1400^{\circ} \mathrm{C}$, measured at $100 \mathrm{kHz}$ and room temperature.

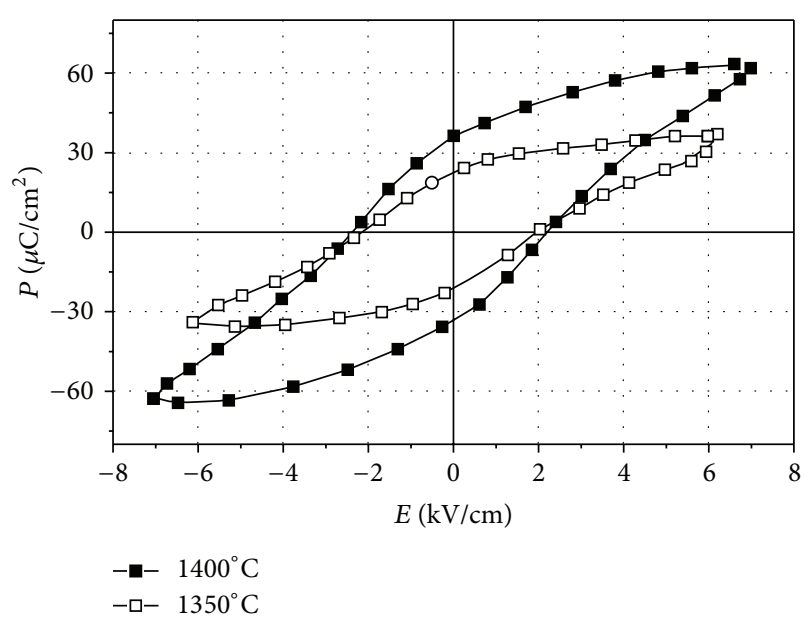

FIGURE 10: Polarization versus electric field for BZT sintered at $1400^{\circ} \mathrm{C}$, measured at $50 \mathrm{~Hz}$ and room temperature. 
at room temperature) were obtained. These results show an efficient way in the synthesis of BZT ceramics as compared to other proceedings reported in the literature.

Moreover, several common features of these ceramics were found in our samples, summarized as follows. The dielectric constant drops when the frequency rises at the range from $1 \mathrm{kHz}$ to $1 \mathrm{MHz}$. The Curie temperature does not change with frequency but grows slightly with sintering temperature increasing. Furthermore, sintering at $1400^{\circ} \mathrm{C}$ improves the dielectric properties (rise of $\varepsilon$ and decreasing of $\mathrm{D}$ ) with regard to sintering at $1350^{\circ} \mathrm{C}$.

\section{References}

[1] Y. Xu, Ferroelectric Materials and Their Applications, North Holland, 1991.

[2] M. T. Sebastian, Dielectric Materials for Wireless Comunications, Elsevier, 2008.

[3] R. Frank, Understanding Smart Sensors, Artech House, 2000.

[4] B. Jaffe, W. R. Cook, and H. Jaffe, Piezoelectric Ceramics, Academic Press, 1971.

[5] A. Moulson and J. Herbert, Electroceramics: Materials-Properties-Applications, John Wiley \& Sons, 2003.

[6] U. Weber, G. Greuel, U. Boettger, S. Weber, D. Hennings, and R. Waser, "Dielectric properties of $\mathrm{Ba}(\mathrm{Zr}, \mathrm{Ti}) \mathrm{O}_{3}$-based ferroelectrics for capacitor applications," Journal of the American Ceramic Society, vol. 84, pp. 759-766, 2001.

[7] K.-i. Mimura, T. Naka, T. Shimura, W. Sakamoto, and T. Yogo, "Synthesis and dielectric properties of $(\mathrm{Ba}, \mathrm{Ca})(\mathrm{Zr}, \mathrm{Ti}) \mathrm{O}_{3}$ thin films using metal-organic precursor solutions," Thin Solid Films, vol. 516, no. 23, pp. 8408-8413, 2008.

[8] A. Simon, J. Ravez, and M. Maglione, "Relaxor properties of $\mathrm{Ba}_{0.9} \mathrm{Bi}_{0.067}\left(\mathrm{Ti}_{1-x} \mathrm{Zr}_{x}\right) \mathrm{O}_{3}$ ceramics," Solid State Sciences, vol. 7, no. 8, pp. 925-930, 2005.

[9] S. Lee, M. Kwak, S. Moon, H. Ryu, Y. Kim, and K. Kang, Integrated Ferroelectrics, vol. 77, pp. 93-99, 2005.

[10] C. Suryanarayana, Progress in Materials Science, vol. 46, pp. 1184, 2001.

[11] J. Lee, M. Choi, N. Hung et al., Ceramics International, vol. 33, pp. 1283-1286, 2007.

[12] R. Rajkhowa, L. Wang, and X. Wang, "Ultra-fine silk powder preparation through rotary and ball milling," Powder Technology, vol. 185, no. 1, pp. 87-95, 2008.

[13] C. B. Reid, J. S. Forrester, H. J. Goodshaw, E. H. Kisi, and G. J. Suaning, "A study in the mechanical milling of alumina powder," Ceramics International, vol. 34, no. 6, pp. 1551-1556, 2008.

[14] C. Gomez-Yañez, C. Benitez, and H. Balmori-Ramirez, "Mechanical activation of the synthesis reaction of $\mathrm{BaTiO}_{3}$ from a mixture of $\mathrm{BaCO}_{3}$ and $\mathrm{TiO}_{2}$ powders," Ceramics International, vol. 26, no. 3, pp. 271-277, 2000.

[15] A. Beauger, J. C. Mutin, and J. C. Niepce, "Synthesis reaction of metatitanate $\mathrm{BaTiO}_{3}$-part 1 Effect of the gaseous atmosphere upon the thermal evolution of the system $\mathrm{BaCO}_{3}-\mathrm{TiO}_{2}$," Journal of Materials Science, vol. 18, no. 10, pp. 3041-3046, 1983.

[16] L. B. Kong, J. Ma, H. Huang, R. F. Zhang, and W. X. Que, "Barium titanate derived from mechanochemically activated powders," Journal of Alloys and Compounds, vol. 337, no. 1-2, pp. 226-230, 2002.

[17] L. Templeton and J. Pask, "Formation of $\mathrm{BaTiO}_{3}$ from $\mathrm{BaCO}_{3}$ and $\mathrm{TiO}_{2}$ in air and in $\mathrm{CO}_{2}$," Journal of the American Ceramic Society, vol. 42, pp. 212-216, 1959.
[18] V. Berbenni, A. Marini, and G. Bruni, "Effect of mechanical milling on solid state formation of $\mathrm{BaTiO}_{3}$ from $\mathrm{BaCO}_{3}-\mathrm{TiO}_{2}$ (rutile) mixtures," Thermochimica Acta, vol. 374, no. 2, pp. 151$158,2001$.

[19] A. West, Solid State Chemistry and Its Applications, John Wiley \& Sons, 1992.

[20] F. Moura, A. Z. Simões, B. D. Stojanovic, M. A. Zaghete, E. Longo, and J. A. Varela, "Dielectric and ferroelectric characteristics of barium zirconate titanate ceramics prepared from mixed oxide method," Journal of Alloys and Compounds, vol. 462, no. 1-2, pp. 129-134, 2008.

[21] A. Ioachim, M. I. Toacsan, M. G. Banciu et al., "Synthesis and properties of $\mathrm{Ba}\left(\mathrm{Zn}_{1 / 3} \mathrm{Ta}_{2 / 3}\right) \mathrm{O}_{3}$ for microwave and millimeter wave applications," Thin Solid Films, vol. 516, no. 7, pp. 1558$1562,2008$.

[22] T. Maiti, R. Guo, and A. S. Bhalla, "Structure-property phase diagram of $\mathrm{BaZr}_{x} \mathrm{Ti}_{1-x} \mathrm{O}_{3}$ system," Journal of the American Ceramic Society, vol. 91, no. 6, pp. 1769-1780, 2008.

[23] N. Nanakorn, P. Jalupoom, N. Vaneesorn, and A. Thanaboonsombut, "Dielectric and ferroelectric properties of $\mathrm{Ba}\left(\mathrm{Zr}_{x} \mathrm{Ti}_{1-x}\right) \mathrm{O}_{3}$ ceramics," Ceramics International, vol. 34, no. 4, pp. 779-782, 2008.

[24] Z. Yu, C. Ang, R. Guo, and A. S. Bhalla, "Piezoelectric and strain properties of $\mathrm{Ba}\left(\mathrm{Ti}_{1-x} \mathrm{Zr}_{x}\right) \mathrm{O}_{3}$ ceramics," Journal of Applied Physics, vol. 92, no. 3, 1489 . 

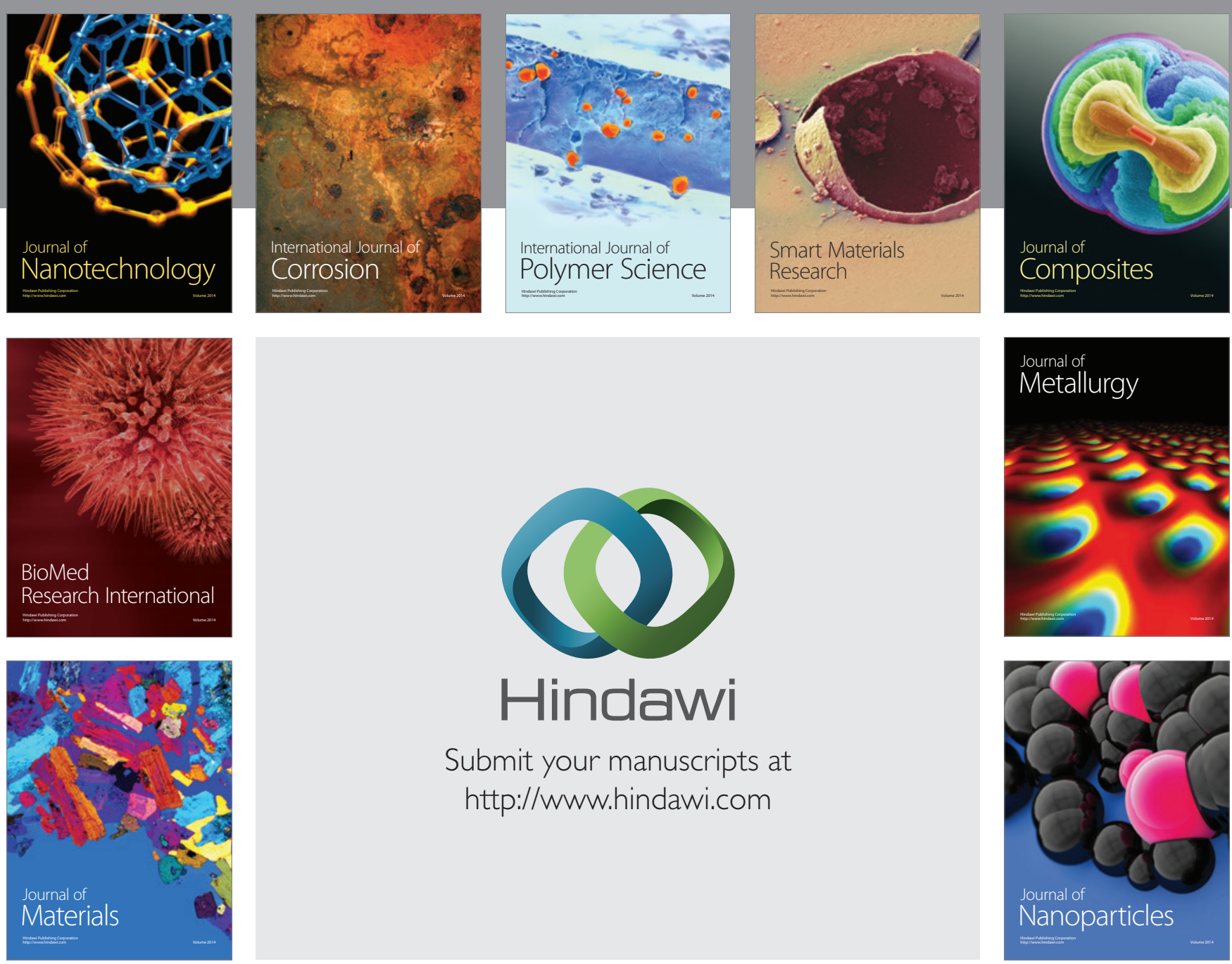

Submit your manuscripts at http://www.hindawi.com
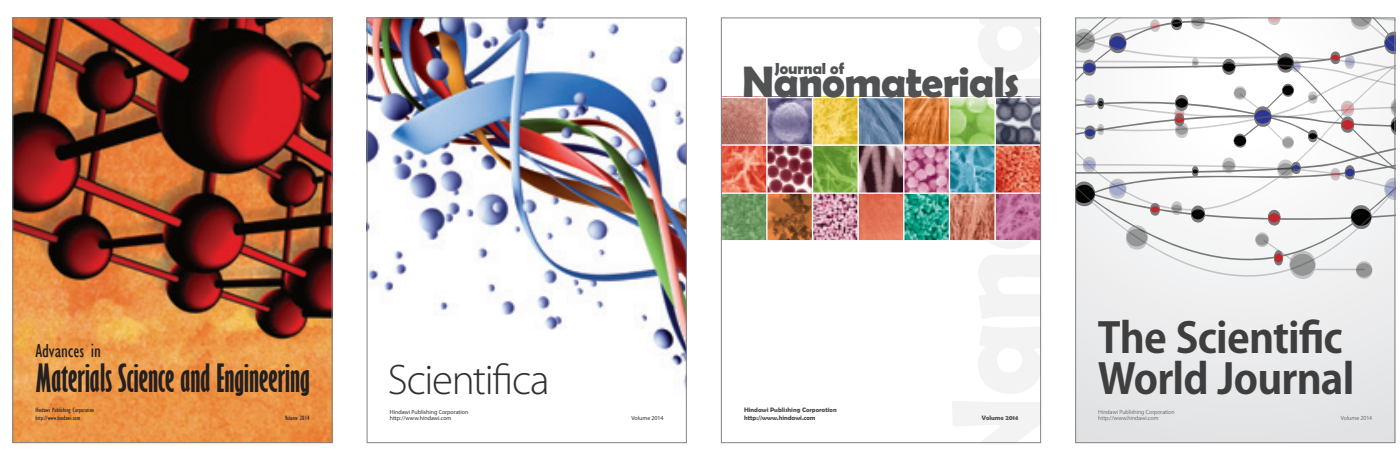

\section{The Scientific World Journal}
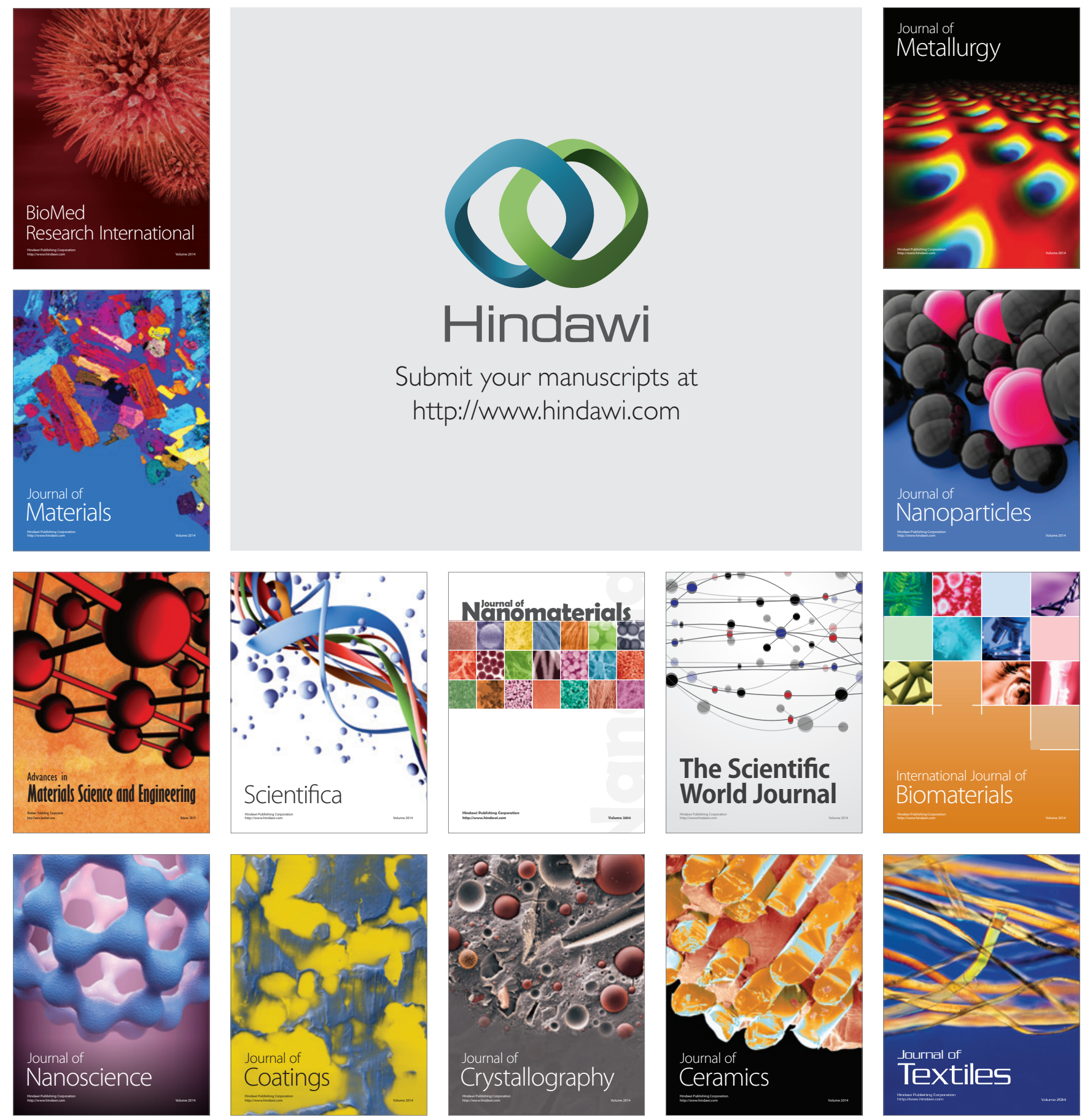